\title{
OS CIRCUITOS DA ECONOMIA E O COMÉRCIO ATACADISTA NA RUA GOVERNADOR SAMPAIO/FORTALEZA (CE)
}

\author{
LUCAS DE HOLANDA ROLIM \\ Mestrando em Geografia, Programa de Pós-Graduação em Geografia - ProPGeo, \\ Universidade Estadual do Ceará ${ }^{1}$ \\ lucasdehrolim@gmail.com
}

DENISE CRISTINA BOMTEMPO

Doutora em Geografia, Professora dos cursos de Graduação e Pós-Graduação em Geografia da Universidade Estadual do Ceará ${ }^{1}$ denise.bomtempo@uece.br

\begin{abstract}
RESUMO: No período técnico-científico-informacional as mudanças ocorrem de forma veloz e em escala global, mas não atingem todos os lugares na mesma velocidade, diferenciando-os no espaço e no tempo. A leitura das atividades econômicas por via da economia urbana é uma das maneiras possíveis de interpretar a organização da atividade a qual deseja estudar. Nesse contexto, este artigo tem como objetivo caracterizar o atual comércio atacadista desenvolvido na Rua Governador Sampaio, Centro da cidade de Fortaleza/CE, por meio da articulação dos circuitos da economia urbana, entendido como um elo imprescindível aos circuitos. Para alcançarmos os objetivos propostos, utilizamos os seguintes procedimentos metodológicos: seleção das variáveis analíticas, secundárias e empíricas, levantamento bibliográfico e de dados; organização de banco de dados e trabalho de campo. A justificativa da análise parte do entendimento que o comércio atacadista desenvolvido na referida via é secular e teve sua origem na formação da praça comercial de Fortaleza, que atualmente é o seu Centro tradicional, e antecede às mudanças que o setor atacadista passou nos últimos vintes anos, metamorfoseando e coexistindo com as modernizações.

Palavras-chave: Circuitos da Economia; Comércio Atacadista; Rua Governador Sampaio.
\end{abstract}

\section{ECONOMIC CIRCUITS AND STREET WHOLESALERS GOVERNADOR SAMPAIO / FORTALEZA (CE)}

\begin{abstract}
In the technical-scientific-informational period, changes occur quickly and on a global scale, but do not reach all places at the same speed, differentiating them in space and time. Reading economic activities via the urban economy is one of the possible ways of interpreting the organization of the activity you want to study. In this context, this article aims to characterize the current wholesale trade developed at street Governador Sampaio, downtown of Fortaleza/CE, through the articulation of the urban economy circuits, understood as an essential link to the circuits. To achieve the proposed objectives, we use the following methodological procedures: selection of analytical, secondary and empirical variables, bibliographic and data survey; database organization and fieldwork. The justification of the analysis is based on the understanding that the wholesale trade developed on this route is secular and had its origin in the formation of the commercial square of Fortaleza, which is currently its traditional Center, and precedes the changes that the wholesale sector has undergone in the last twenty years, metamorphosing and coexisting with modernizations.
\end{abstract}

Keywords: Circuits of the Economy; Wholesale; Governador Sampaio Street.

\section{CIRCUITOS ECONÓMICOS Y MAYORISTAS CALLEJEROS GOBERNADOR SAMPAIO / FORTALEZA (CE)}

RESUMÉN: En el período técnico-científico-informativo, los cambios se producen rápidamente y a escala global, pero no llegan a todos los lugares a la misma velocidad, diferenciándolos en el espacio y el tiempo. Leer las actividades económicas a través de la economía urbana es una de las posibles formas de interpretar la organización de la actividad que se quiere estudiar. En este contexto, este artículo tiene como objetivo caracterizar el comercio mayorista actual que se desarrolla en la calle Governador Sampaio, en el centro de Fortaleza/CE, a través de la articulación de los circuitos de economía urbana, entendido como un eslabón esencial a los circuitos. Para lograr los objetivos propuestos, utilizamos los

1 Endereço para correspondência: Avenida Dr. Silas Munguba, 1700, Campus do Itaperi, CEP: 60714-903, Fortaleza-CE.

Lucas de H. Rolim, Denise C. Bomtempo. Os circuitos da economia e o comércio atacadista na Rua Governador Sampaio/Fortaleza(CE) Brazilian Geographical Journal: Geosciences and Humanities research medium, Ituiutaba, v. 11, n. 2, p. 193-202, ago./dez. 2020 
siguientes procedimientos metodológicos: selección de variables analíticas, secundarias y empíricas, relevamiento bibliográfico y de datos; organización de bases de datos y trabajo de campo. La justificación del análisis se fundamenta en el entendimiento de que el comercio mayorista desarrollado en esta ruta es secular y tuvo su origen en la formación de la plaza comercial de Fortaleza, que actualmente es su tradicional Centro, y antecede los cambios que ha experimentado el sector mayorista en los últimos veinte años, metamorfoseando y conviviendo con modernizaciones.

Palabras clave: Circuitos de la Economía; Venta al por mayor; Calle Governador Sampaio.

\section{INTRODUÇÃO}

Realizar a leitura das atividades econômicas relativas ao comércio, mais especificamente ao comércio atacadista, é uma tarefa múltipla. As mudanças no espaço global proporcionadas no período presente por meio do desenvolvimento técnico-cientificoinformacional comprimem as distâncias e aceleram os fluxos, que ocasionam mudanças importantes na leitura do espaço.

As cidades, sobretudo, as metrópoles, são as mais atingidas por essas mudanças. A economia urbana é uma das maneiras possíveis de interpretar a organização da atividade estudada. Nesse contexto, este trabalho tem como objetivo caracterizar o atual comércio atacadista desenvolvido na Rua Governador Sampaio, Centro da cidade de Fortaleza-CE (Cartograma 1), por meio da articulação dos circuitos da economia urbana, entendido como um elo imprescindível. Vale destacar que o comércio atacadista estudado é o de mercearia básica ou mercearil (alimentos, bebidas, higiene pessoal e limpeza) classificação designada pela Associação Brasileira de Distribuidores e Atacadistas (ABAD). Para chegarmos ao objetivo proposto foram realizados os seguintes procedimentos metodológicos: a) seleção das variáveis analíticas, secundárias e empíricas; b) levantamento bibliográfico e de dados; c) organização de banco de dados e d) trabalho de campo. Com o intuito de apresentar as discussões e os resultados do trabalho realizado, organizamos esse texto em três partes mais esta introdução e considerações finais.

Cartograma 1 - Localização da Rua Governador Sampaio na cidade de Fortaleza/CE

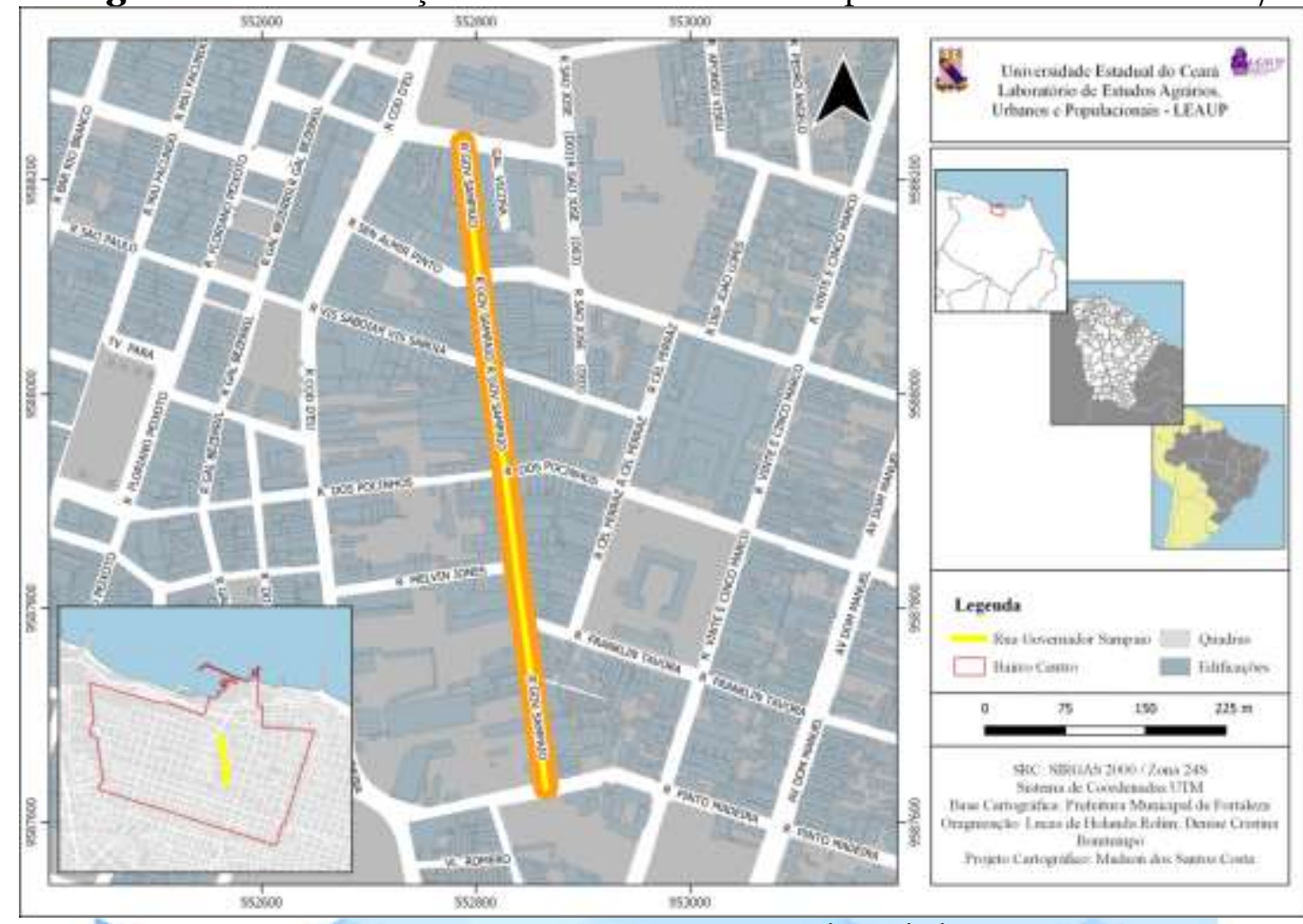

Fonte: ROLIM, Lucas; BOMTEMPO, Denise Cristina. 2019.

Lucas de H. Rolim, Denise C. Bomtempo. Os circuitos da economia e o comércio atacadista na Rua Governador Sampaio/Fortaleza(CE) Brazilian Geographical Journal: Geosciences and Humanities research medium, Ituiutaba, v. 11, n. 2, p. 193-202, ago./dez. 2020 
Na primeira parte, embasamos nossa discussão na teoria dos circuitos da economia urbana proposta pelo autor Milton Santos (1970). O autor referenciado entende que o comércio atacadista é um elo imprescindível entre os circuitos superior, superior marginal e inferior. Desse modo, na primeira parte deste texto, realizamos uma discussão acerca do caráter intermediador dos atacadistas e distribuidores com as demais atividades que compõem o circuito da economia urbana.

Na segunda parte, denominada "mudanças e permanências no comércio atacadista da Rua Governador Sampaio", a fim de elucidar algumas mudanças e permanências da atividade atacadista no referido espaço, que coexistem, organizamos o texto em duas partes para compreender: os motivos da permanência da atividade atacadista no Centro da cidade de Fortaleza, bem como as modernizações e as coexistências da atividade no Rua em apreço.

Ao concluir o texto, caracterizamos as atividades desenvolvidas na Rua Governador Sampaio, o espaço do atacado, somado aos dados obtidos em campo por meio de observação e entrevistas, que utiliza a classificação da $\mathrm{ABAD}$ para caracterizar as atividades atacadistas desenvolvidas pelos estabelecimentos de mercearia básica em: distribuidoras, de balcão e autosserviço e articulamos as suas atividades aos circuitos da economia urbana.

Desse modo, é possível afirmar que apesar de "decadente", o comércio atacadista continua com expressividade no espaço do atacado, articula diversas atividades, sobretudo, do circuito inferior: restaurantes, lanchonetes e comércio ambulante, gera diversos fluxos intra e interurbano, bem como realiza abastecimento de pequenos varejos, bares, lanchonetes e restaurantes dispersos no entorno do Centro, bairros periféricos da cidade, municípios da Região Metropolitana de Fortaleza (RMF) e outros municípios do Estado.

\section{OS CIRCUITOS DA ECONOMIA E O COMÉRCIO ATACADISTA COMO ELO}

As mudanças ocorridas no final do século XX e início do século XXI no espaço global são notórias, resultado da reinvenção do modo de produção capitalista para a obtenção cada vez maior de lucros. Elas impactam na vida cotidiana das cidades, sobretudo, as metrópoles, que "[...] contêm diferentes divisões do trabalho que coexistem e que por sua vez estabelecem relações diferenciadas com seu meio construído" (MONTENEGRO, 2011, p. 10).

Nas metrópoles a dinâmica da globalização ${ }^{2}$ se expressa na paisagem - por meio do desenvolvimento da modernidade e multiplicação da pobreza, contribuindo de forma expressiva para a complexidade metropolitana. Ela não apaga o passado, mas modifica seu significado e agrega a ele novas variáveis que contribuem para promover outras desigualdades (SILVEIRA, 2009).

Assim, para caracterizar a economia urbana, na atualidade, é necessário refletir sobre as novas configurações que a globalização impõe ao espaço urbano, tendo em vista que, conforme Montenegro (2011) afirma, os impactos da globalização são fortemente percebidos nas metrópoles, e estes, estão impressos na sua paisagem urbana.

Mas como no período atual conseguimos realizar a leitura da economia urbana, ou seja, da cidade em movimento? Quais os temas e as variáveis relevantes para compreender a complexidade presente na sociedade urbana, sobretudo, nas metrópoles, que se faz e refaz de maneira rápida e fluída?

Múltiplos são os caminhos que possibilitam essa leitura, o que elegemos perpassa pelas dimensões econômicas, políticas e sociais. Assim, é preciso considerar as mudanças e as permanências decorrentes das ações dos agentes envolvidos na produção e na organização do espaço por meio da interação espacial, pois no período da globalização se revelam de maneira complexa.

${ }^{2}$ Santos (2018) afirma que a base da globalização e das mudanças contemporâneas do espaço global abarca três unicidades: da técnica, do tempo e do motor da vida econômica e social.

Lucas de H. Rolim, Denise C. Bomtempo. Os circuitos da economia e o comércio atacadista na Rua Governador Sampaio/Fortaleza(CE) Brazilian Geographical Journal: Geosciences and Humanities research medium, Ituiutaba, v. 11, n. 2, p. 193-202, ago./dez. 2020 
De acordo com Corrêa (2006), entendemos por interações espaciais

[...] um amplo e complexo conjunto de deslocamentos de pessoas, mercadorias, capital e informação sobre o espaço geográfico. Podem apresentar maior ou menor intensidade, variar segundo a freqüência de ocorrência e, conforme a distância e direção caracterizar-se-á por diversos propósitos e se realizará através de diversos meios e velocidade (CORREA, 2006, p. 279).

Assim, embasaremos essa caracterização considerando a teoria dos circuitos da economia urbana de Milton Santos, que foi desenvolvida na década de 1970, e nela o autor afirma existir, nos países subdesenvolvidos, dois circuitos da economia urbana. O circuito superior (com uma modernização mais direta) e o circuito inferior (com uma modernização mais indireta), pelos quais são "[...] responsáveis não apenas pelo processo econômico urbano, mas também pelo processo de organização espacial” (SANTOS, 2011, p. 126).

Ainda de acordo com Santos (2018), o circuito superior é formado por bancos, indústria urbana, comércio de exportação e importação, comércio e serviços modernos, acrescentado do comércio atacadista e transportes - que são os intermediários. Utiliza tecnologia importada e de alto desempenho, capital intensivo e extensivo, organização burocrática, em que os preços em geral são fixos e a relação com a clientela é impessoal.

Em contrapartida, o circuito inferior é o formado por atividades manufatureiras compostas, predominantemente, por trabalho artesanal, com pequenas quantidades de mercadorias tanto no comércio como na fabricação. A tecnologia é de "trabalho intensivo", com pouco capital, os preços são negociáveis, a relação com o consumidor é pessoal e muitas vezes personalizada e a atividade é realizada local ou localmente adaptada.

Os circuitos da economia urbana são múltiplos, mas são interdependentes e, constituem um conjunto de atividades desenvolvidas com graus diferenciados de capital, tecnologia e organização resultantes da modernização capitalista e da desigualdade na distribuição de renda. E nessa interdependência que se constrói, também, a dependência das demandas e das ofertas, resultado dos desiguais graus de capital de cada circuito, que se materializam na vida social e econômica das cidades.

De acordo Santos (2018), os circuitos são diferenciados pelas suas atividades em três categorias: puras, impuras e mistas. As atividades puras estão associadas aos serviços, comércio e indústria - todos modernos. As atividades impuras, que se beneficiam das vantagens locacionais do território, mas seu comando parte de outro local, estão associadas ao comércio e indústria de exportação. Já as atividades do tipo mistas, que mantém conexão com os dois circuitos, estão associadas aos atacadistas e aos transportadores. $\mathrm{O}$ atacadista age como elo entre a demanda e a oferta, segundo o referido autor, na cadeia dos intermediários ele fica no topo, sendo, ao mesmo tempo, elemento do circuito superior, configurando-se como elo para o circuito inferior.

O atacadista age como um elo entre o circuito superior e o inferior por ele fornecer crédito em forma de mercadoria, já que a diferenciação acentuada da renda gera uma numerosa massa de população pobre que não tem acesso ao dinheiro líquido no banco, dando ao atacadista um papel privilegiado no abastecimento (SANTOS, 2018). Que se deve ao fato de que ele pode adquirir de um fornecedor um grande estoque de mercadorias que, ao longo de um mês ou semanas, poderão ser distribuídas de forma a atender às demandas dos varejistas em quantidades e frequências variadas.

Dessa forma, quanto mais baixo na hierarquia dos atacadistas, mais as operações são diminuídas e os prazos também, aumentando riscos e as taxas de juros, porém a dependência é mutua (XAVIER, 2009). Os atacadistas não subsistiriam sem serem fornecedores dos pequenos comerciantes, na medida em que estes, sendo constantes devedores e compradores, permitem aos atacadistas um contínuo reabastecimento e uma saída permanente de produtos, que lhes assegurem a mobilidade de seu capital e uma acumulação maior (XAVIER, 2009, p. 13).

Lucas de H. Rolim, Denise C. Bomtempo. Os circuitos da economia e o comércio atacadista na Rua Governador Sampaio/Fortaleza(CE) 
Na perspectiva dos dois circuitos da economia urbana, compreendemos a cidade como um sistema contraditório, onde os agentes vinculados ao comércio atacadista realizam suas atividades, por um lado, marcada pelo poder hegemônico do capital e por outro lado, marcado pela resistência e sobrevivência da população pobre. Montenegro (2006, p. 12) esclarece, "[...] a cidade não pode ser confundida ou identificada com uma única área de mercado onde se realiza o trabalho mais moderno", pois isso simplificaria sua dinâmica, e ela é muito mais complexa, é o local de produção e reprodução social.

Por conseguinte, Silveira (2009) esclarece ainda mais que,

El extraordinario crecimiento del medio construido urbano en el período de la globalización tiene relación directa con la expansión de los circuitos de la economía urbana. El circuito superior es productor y usuario de los macrosistemas técnicos, lo cual obliga una expansión artificial de la ciudad, pues la cooperación que completa su división territorial del trabajo se hace a grandes distancias y rápidas velocidades. El circuito inferior es expulsado para áreas menos valorizadas, pero esa nueva configuración de la ciudad le resulta también un abrigo (SILVEIRA, 2009, p. 451).

Assim, quando analisamos as metrópoles, não podemos omitir a presença expressiva do circuito inferior da economia urbana, pois elas, dentro da sua complexidade, não se constituem apenas por setores hegemônicos, "[...] sino también por un circuito inferior, que no es un freno a la modernización sino su resultado, e incluso, por un circuito superior marginal, nacido sobre todo en función de la relevancia que adquiere la circulación" (SILVEIRA, 2004, p. 9).

A autora ainda enfatiza:

El crecimiento de un circuito superior marginal residual se da por la incapacidad de modernizarse al ritmo impuesto por la época. Pero, paralelamente, la normalización, la relevancia y precedencia del trabajo intelectual, el carácter científico de las actividades y la expansión de los consumos son pilares del crecimiento de un circuito superior marginal emergente. Por eso, este circuito podría ser visto como un laboratorio de la sustitución de una división territorial del trabajo por otra. La decadencia y emergencia de profesiones y empresas vinculadas a las formas hegemónicas de hacer y de mandar alcanzan directamente el circuito superior marginal. Mientras ciertos saberes se desvalorizan, otros surgen (SILVEIRA, 2004, p. 12).

Diante disso, Silveira (2004) destaca que quanto maior a população de uma cidade, maior, mais segmentado e fragmentado é seu mercado, e isso leva apreensão de áreas de diversidades e áreas de especializações.

Nas áreas de diversidades ocorre uma especialização do trabalho e com isso uma multiplicidade de circuitos. São áreas de grande circulação, como exemplifica a autora - os próprios centros urbanos e nelas os diferentes circuitos se cruzam - destaque para o circuito inferior e o superior marginal, criando um mercado segmentado. Essas áreas não são características apenas das metrópoles.

Nas áreas de especializações ocorre diferente. Elas são um fenômeno da ocorrência da metropolização. Nesse caso, o trabalho se especializa dentro de um mesmo circuito da produção, coexistindo com os circuitos da economia urbana e essa especialização é causa e consequência da concentração de espaços de fluxos (transporte, comunicação, mercadorias específicas e finanças).

Dessa maneira, para entender os circuitos da economia urbana vinculado ao comércio atacadista desenvolvido na Rua Governador Sampaio, nossa análise está baseada na perspectiva da teoria dos circuitos da economia urbana (SANTOS, 2008), levando em 
consideração o circuito superior e o inferior adicionado ao superior marginal, que tem características dos dois circuitos.

Assim, com um crescimento notório da atividade atacadista nos últimos vinte anos, e pela presença dessa atividade no Centro tradicional da cidade de Fortaleza, sobrevivendo e propagando o elo entre os circuitos da economia urbana, em particular os atacadistas distribuidores, de balcão e autosserviço de mercearia básica, que esse texto se empenha, frente às diversas mudanças na produção, distribuição e consumo e entrada das redes atacadistas em Fortaleza.

\section{MUDANÇAS E PERMANÊNCIAS NO COMÉRCIO ATACADISTA DA RUA GOVERNADOR SAMPAIO}

As mudanças que ocorreram no país desde a década de 1990 com o controle inflacionário, a estabilidade da moeda, a abertura de mercado aumentando a concorrência e os novos comportamentos de consumo tem modificado a forma de viver, sobretudo, nas metrópoles.

O Centro da cidade de Fortaleza foi palco de intensas mudanças no perfil de consumo - passando de Centro das atividades hegemônicas para Centro do consumo de periferia e, nessas mudanças, a atividade atacadista desenvolvida na Rua Governador Sampaio, mesmo não exercendo mais uma centralidade, permanece.

A fim de elucidar algumas mudanças e permanências da atividade atacadista no referido espaço, dividimos este tópico em duas partes a fim de explicar os motivos da permanência, lido como resistência, e as modernizações e coexistências da atividade atacadista.

\section{A resistência de uma atividade secular}

A história do Centro perpassa pela história de Fortaleza, pois ele era a própria cidade. Assim, para entender as atuais configurações do comércio atacadista é necessário entender a história da formação socioespacial e econômica de Fortaleza.

No início da colonização, dada a condição de semiaridez, o Ceará, num primeiro momento, não despertou atenção dos colonizadores portugueses, tanto para exploração de recursos naturais como para fabricação de produtos semi faturados que pudessem ser dirigidos ao mercado externo. Esses fatores contribuíram, entre outros, para a diferenciação da estrutura urbana cearense em relação à formação urbana dos demais estados que compõem a região Nordeste do país.

Dantas e Silva (2009) esclarecem na exposição:

Não dispunha [o estado do Ceará] de uma cidade principal, mas de um conjunto de cidades interioranas articuladas e especializadas na produção e comercialização da carne seca, ficando sua capital litorânea isolada na zona costeira, sem estabelecer vínculos com outros centros urbanos coloniais (DANTAS e SILVA, 2009, p. 3).

As cidades interioranas - como Aracati, Sobral, Crato e Icó, não eram articuladas com a capital, e se desenvolveram de forma diferente das cidades litorâneas. A criação de gado era a atividade predominante da população dessas cidades e tinha como objetivo fornecer carne, couro e animais de tração para as regiões canavieiras. Os donos de fazendas se dedicavam também ao plantio de milho, feijão e mandioca, mas como culturas de subsistência.

"Fortaleza, até o final do século XVII, era uma pequena e acanhada vila sem nenhuma expressão econômica, tendo apenas o papel de capital administrativa" (COSTA, 2009, p. 143). Não nasceu hegemônica (Linhares, 1992), diferente de outras cidades brasileiras que tiveram 
sua origem ainda no período colonial. Seu processo de formação urbana se inseriu numa lógica militar - garantindo a posse do território e defesa do litoral (SILVA E DANTAS, 2009).

A cotonicultura foi um fator marcante para ascensão de Fortaleza, no qual fortaleceu o papel de centralidade na rede urbana cearense, bem como sua economia, tendo em vista que “[...] a lavoura algodoeira, à proporção que se expandia provocava a projeção de Fortaleza como centro urbano" (SILVA, 2009, p. 88). A produção de algodão no Estado para abastecer o mercado europeu que estava em crescente processo de industrialização só foi possível por causa do conflito interno - guerra de secessão - nos Estados Unidos da América, que o impossibilitou a produzir na escala da demanda europeia.

Ainda no século XIX, Fortaleza se tornou o maior centro exportador e importador do estado. A cotonicultura foi responsável pela estruturação de um sistema ferroviário que permitiu a capital interligasse com os municípios produtores de algodão do estado. A respeito disso, Silva acentua:

A construção da ferrovia para o interior através do Sertão Central representou a fase de acentuado crescimento demográfico de Fortaleza. A cidade já nesse tempo possuía suas dificuldades, principalmente aquelas ligadas à construção do seu porto - fator fundamental para a atividade exportadora (SILVA, 2009, p. 88).

Ressaltamos que a cotonicultura teve reflexos significativos para a economia da cidade - desde a acumulação de capital, às mudanças no espaço urbano e ao modo de vida da sociedade. Endossamos a exposição de Souza:

O comércio de exportação do algodão explica o desenvolvimento da capital e a extensão de sua área de influência. Com efeito, organizando-se em Fortaleza o comércio exportador de algodão, o raio de projeção da cidade ampliou-se para além das zonas produtoras de Uruburetama e Baturité estendendo-se para o sertão, acompanhando a própria extensão da cultura algodoeira (SOUZA, 2009, p. 22).

O porto após sua melhoria passou a ter um papel fundamental na dinâmica comercial de Fortaleza, pois a cidade começou a drenar as mercadorias produzidas em outros municípios do estado, além de ser entrada para os produtos vindos de fora, principalmente dos países europeus. A circulação de mercadorias e capital se tornou mais vultosa, por meio do levantamento das atividades do Porto da cidade de Fortaleza, que naquele momento, era o principal escoadouro da produção do Estado do Ceará, "[...] fazendo com que a capital se inserisse nas principais rotas comerciais do mundo" (QUEIROZ, 2011, p. 29).

A dinâmica que os novos equipamentos - ferrovia, ligando Fortaleza a outros municípios do estado e porto, drenando a produção algodoeira e dinamizando o comércio de importação e exportação, deram à cidade foi fundamental para o desenvolvimento de outras funções para além da já existente (administrativa) - exemplo, a função comercial e a função de serviços públicos.

O comércio, voltado para exportação e importação de mercadorias, fortaleceu-se, com isso, surgiram várias casas comerciais, muitas com investimentos de capital estrangeiro. Os investimentos estrangeiros em Fortaleza foram de extrema importância para o desenvolvimento da capital do estado que, basicamente, era composta pelo seu atual Centro tradicional. Esses investimentos foram responsáveis pelo desenvolvimento das casas de exportação-importação (LEMENHE, 1985) que possuíam uma diversificação na mercadoria comercializada e diferentes equipamentos.

O comércio atacadista ganhou destaque (QUEIROZ, 2011) contando com diversos armazéns concentrados da área do porto, na Praça do Ferreira e nas Ruas Imperador, Barão do Rio Branco e Major Facundo, tendo como função de armazenar e repassar os produtos manufaturados, matérias-primas, gêneros alimentícios e artigos diversos para os consumidores, atravessadores e comerciantes, conforme Tabela 1. 
Tabela 1 - Número de Armazéns e Escritórios em Fortaleza (1904 a 1907)

\begin{tabular}{ccccc} 
Atividade & $\mathbf{1 9 0 4}$ & $\mathbf{1 9 0 5}$ & $\mathbf{1 9 0 6}$ & $\mathbf{1 9 0 7}$ \\
\hline Armazéns de depósitos & 56 & 50 & 52 & 45 \\
Armazéns de estivas & 16 & 22 & 23 & 18 \\
Armazéns de fazendas & 16 & 25 & 32 & 34 \\
Escritórios comerciais & 19 & 25 & 28 & 22 \\
Agências & 8 & 11 & 14 & 18 \\
Total & $\mathbf{1 1 5}$ & $\mathbf{1 3 3}$ & $\mathbf{1 4 9}$ & $\mathbf{1 3 7}$ \\
\hline
\end{tabular}

Fonte: QUEIROZ (2011, p. 41). Adaptado pelos autores. ROLIM, Lucas de Holanda e BOMTEMPO, Denise Cristina. 2019.

A configuração urbana do Centro de Fortaleza, que até então, ainda era a própria cidade de Fortaleza, foi marcada por essas atividades desempenhadas por diversos sujeitos, muitos deles vindo de outros estados brasileiros e de outros países. Eram portugueses, ingleses, italianos, libaneses que, entre tantos outros imigrantes, estabeleceram-se em Fortaleza, principalmente no início do século XIX.

Como parte constituidora e dinamizadora do comércio em Fortaleza, temos a presença desses sujeitos e também de duas importantes instituições comerciais na cidade: a Junta Comercial do Ceará (JUCEC) e a Associação Comercial do Ceará. Dessa forma, a existência dessas sedes comerciais na capital do Estado confirma a importância estratégica de Fortaleza enquanto centro comercial.

A autora, ao pesquisar sobre a produção e o comércio em Fortaleza no final do século XIX e início do século XX, analisa os Almanaques do Estado do Ceará, dessa forma, dá excelente subsídio para entender a formação da atividade comercial no Centro, sobretudo, atacadista - que é nosso objetivo de estudo, quando realiza catalogação dos estabelecimentos comerciais matriculados na cidade no final do século XX.

Além da função administrativa, a cidade adquiriu outras funções - de comércio, habitação e de lazer, principalmente para a população mais rica. O comércio se consolidou a partir da segunda metade do século XIX em consonância com o mesmo período de desenvolvimento econômico do país, presenciando um crescimento e diversificação econômica. Ao estar mais próxima das áreas produtoras, Fortaleza concentrava volume mais expressivo de bens para o mercado interno e externo centralizando as exportações de artigos e produtos manufaturados que circulavam entre as diversas cidades do estado.

Ressaltamos que, na história de Fortaleza, na metade do século XIX, um fator propulsor ao desenvolvimento - a indústria, não teve tanta expressão quanto o comércio. Conforme afirma Costa, "[...] a atividade industrial era inexpressiva, portanto, sem grande significado econômico para a província” (COSTA, 2005, p. 3766).

$\mathrm{O}$ aumento do espaço dedicado à ocupação urbana e à implementação de mais equipamentos urbanos, dá novas nuances às mudanças na estrutura da cidade, o que influi, naturalmente, no transporte de pessoas, de mercadorias e atividades comerciais, e de forma mais geral, da compreensão da cidade por parte de seus habitantes.

De acordo com Silva (2013), diante de tantas mudanças da vida urbana da cidade "[...] já é perceptível, nesse momento, uma significativa mudança funcional na cidade. Ganha precisão de contornos a nova função da cidade - a função comercial, fundamentada em tão indisfarçável prosperidade".

Na estruturação urbana de Fortaleza, é importante destacar o papel dos agentes que organizam o espaço. No caso de Fortaleza, os grandes investidores comerciais, detentores do capital, o Estado, viabilizador de ações estruturantes na ordem dos serviços públicos e outros agentes. Assim, a partir das relações dos diferentes agentes que organizam o espaço (com ações 
intencionais), a cidade, gradualmente, ganha formas diferentes da inexpressividade que tinha no século XVIII.

Um relatório realizado pela Prefeitura Municipal de Fortaleza (PMF) no ano de 2004, intitulado - Estudos das vantagens competitivas do Centro da cidade de Fortaleza, relata a consolidação do comércio varejista e atacadista a partir de 1940, destacando um pólo atacadista no entorno do antigo Mercado Central, que aproveita a circulação de mercadorias pela principal entrada rodoviária da época (a Rua Sena Madureira) e o antigo porto (a Rua Alberto Nepomuceno) e consolida a Rua Governador Sampaio o centro desse movimento de mercadorias (PREFEITURA MUNICIPAL DE FORTALEZA, 2004, p. 4).

Souza (2009) ao tratar a estruturação urbana da cidade, confirma ainda essa centralidade do comércio atacadista na cidade no ano de 1970, sobretudo, na Rua Governador Sampaio, e destaca que $45 \%$ dos estabelecimentos comerciais atacadistas do Estado concentravam-se na cidade de Fortaleza e ocupava $67 \%$ do pessoal na atividade. Porém, também em 1970, a Prefeitura Municipal optou por restringir essa atividade na área, proibindo a concessão de novos alvarás de funcionamento de empresas atacadistas, e dessa forma, a atividade se dispersou para outros bairros da cidade e RMF (Região Metropolitana de Fortaleza).

Segundo a Prefeitura Municipal de Fortaleza (2004), até o ano de 2002 o comércio atacadista do Centro de Fortaleza era o primeiro lugar no ranking de geração de empregos do setor no município, representando $23 \%$ do total de empregos gerados pelo setor. Sua área de competitividade abrangia os bairros da Messejana, Aldeota, Parangaba, Antônio Bezerra e Joaquim Távora. Tendo como principais mercados os bairros da periferia da cidade e outros municípios da Região Metropolitana de Fortaleza (RMF).

Dessa forma, ainda hoje a atividade permanece no Centro de Fortaleza, sobretudo na Rua Governador Sampaio, mesmo com suas desvantagens logísticas e de serviços aos clientes, resistindo e permanecendo por meio da "flexibilidade fiscal" que os comerciantes encontraram na informalidade para acompanhar outros atacadistas de bairros vizinhos e seus bairros concorrentes e vêm transferindo os estabelecimentos para outros interessados sem dar baixa nos registros para perpetuar o direito de funcionamento e "vencer" a barreira imposta pela prefeitura em 1970 que restringe a atividade no local.

\section{A modernização das empresas atacadistas e a coexistência com uma atividade “tradicional": os armazéns}

Uma das melhores formas de entender as inferências na organização do espaço é por meio da modernização (SANTOS, 2008). Ao analisar os fenômenos que nele ocorre é possível datar sua gênese, sua evolução e sua fase atual com maior rigor. Assim, utilizar as modernizações, captadas sob a ótica da periodização da história, evita o erro de compreender uma teoria criada em um determinado período a realidade de outro.

As atuais modernizações derivam do sistema tecnológico, comandadas pelas firmas multinacionais, monopólios e oligopólios (SANTOS, 2008). A importância da tecnologia é imperativa, pois impregna uma capacidade de mudança. Dessa forma, como nunca visto antes na história, duas variáveis percebidas somente em países desenvolvidos encontram nos países subdesenvolvidos uma propagação.

É o caso da informação e do consumo - a primeira servindo ao segundo, cuja sua interrelação encontra fator decisivo na mudança da economia, da sociedade e da organização do espaço. Assim, a expansão da informação se torna mais eficaz que em outros momentos por ter autonomia frente as outras formas de comunicação e, dessa maneira, a participação efetiva no consumo moderno é capaz de atingir mais indivíduos, seja de forma parcial ou ocasional, nas pessoas mais pobres.

Uma nova forma de comércio amplia significativamente sua relevância no cenário nacional e as perspectivas de crescimento para os próximos anos são ainda maiores. Trata-se das empresas atacadistas, que no atual momento da modernização tecnológica e do consumo, busca se reinventar e se adaptar, sobretudo, a um novo perfil de consumidor. 
Xavier (2009) complementa:

O desenvolvimento das empresas atacadistas de produtos de mercearia básica no Brasil acompanha as sucessivas modernizações do território e da sociedade, capitaneadas pelo Estado e pelo mercado que, a partir da segunda metade do século XX, levaram à formação e expansão do meio técnicocientífico e informacional pelo território. Nos anos 1970, a crescente urbanização e gradativa mudança dos hábitos alimentares da população contribuíram para consolidação dos supermercados que, presentes no país desde os anos 1950, se transformaram na forma moderna de consumir os produtos de mercearia básica nas maiores cidades brasileiras (XAVIER, 2009, p. 85).

O papel intermediador dos atacadistas (SANTOS, 2018) se realizava pela oferta de crédito ao pequeno varejo e pela capacidade de comprar grandes lotes de produtos industrializados e vende-los aos bares, aos restaurantes, às mercearias, aos mercantis independentes seguindo as estratégias de comercialização, mas nos últimos vinte anos, com uma estabilidade da moeda, controle inflacionário e os novos comportamentos de consumo (XAVIER, 2009), exigiram das empresas atacadistas maiores empenho em diferentes áreas no intuito de "sobreviver" no mercado. Assim, as modernizações atingem de forma mais direta as ações dessas empresas e edificam novas bases materiais e organizacionais pautadas no incremento de ciência, de tecnologia e de informação.

De maneira geral, as empresas de grande porte e médio porte, caracterizadas pela sua capilaridade no território, seja ela a nível nacional ou regional são as que mais acrescentam nas suas formas materiais e imateriais essas mudanças. Nas empresas da Rua Governador Sampaio, apesar de ocorrerem mudanças expressivas em algumas empresas lá instaladas, percebeu que outras coexistem com as modernizações e permanecem - os armazéns.

A palavra armazém, segundo dicionário etimológico online 3 , vem do arábe "alMakhzan" que significa depósito de armas ou de víveres. Atualmente, ela está relacionada ao local onde são guardadas/estocadas qualquer tipo de mercadoria. Na Rua Governador Sampaio a atividade atacadista é lida como tradicional pelo fato do espaço abrigar a atividade há mais de um século. Os estabelecimentos localizados na Rua ou entorno que desenvolviam as atividades atacadistas na formação da praça comercial da cidade levavam o nome de armazém por estocarem mercadorias para venda. Ainda hoje essa atividade atacadista é desenvolvida, na paisagem urbana percebe-se isso, pois o estabelecimento leva o nome de armazém e a atividade não sofreu tantos impactos das modernizações, coexistindo com os demais estabelecimentos mais modernos (Foto 1 e 2).

Estas fotos demonstram parte do conteúdo dos produtos comercializados na Rua Governador Sampaio e no seu entorno. Podemos perceber que os estabelecimentos permanecem com uma infraestrutura tradicional do ponto de vista da própria arquitetura; da disposição e do tipo de produto comercializado.

As empresas atacadistas desde a década de 1990 buscam melhores formas de se modernizar frente às mudanças no consumo e no comércio varejista. Os novos paradigmas impostos no cenário nacional possibilitaram mudanças no setor atacadista. A logística integrada e a cadeia de suprimentos, as instalações e seus sistemas operacionais (Centro de Distribuição - CD, circulação das mercadorias, o processamento eletrônico da informação e as bases materiais - os maquinários), a diversificação das operações e dos formatos, as marcas próprias, as novas formas de se relacionar com os clientes por meios eletrônicos (os sites B2B) e o gerenciamento de redes de pequenos varejo supermercadista são muitas das modernizações que elas vêm passando ao longo desses trinta anos (XAVIER, 2009).

3 Dicionário Etimológico: https://www.dicionarioetimologico.com.br/

Lucas de H. Rolim, Denise C. Bomtempo. Os circuitos da economia e o comércio atacadista na Rua Governador Sampaio/Fortaleza(CE) Brazilian Geographical Journal: Geosciences and Humanities research medium, Ituiutaba, v. 11, n. 2, p. 193-202, ago./dez. 2020 
Foto 1 - Armazém no entorno da Rua Governador Sampaio

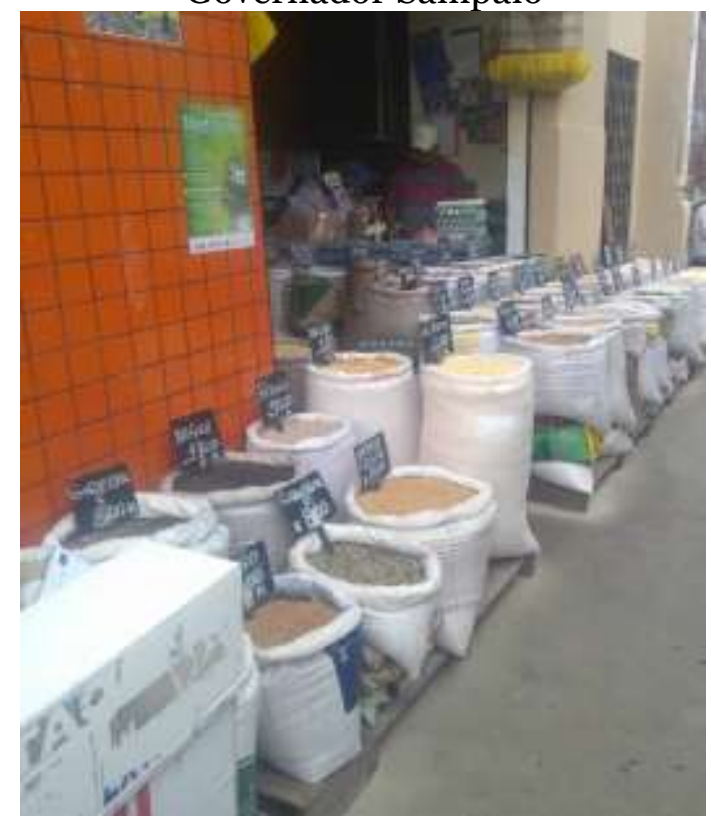

Fonte: Pesquisa Empírica, janeiro, 2018.
Foto 2 - Armazém na Rua Governador Sampaio

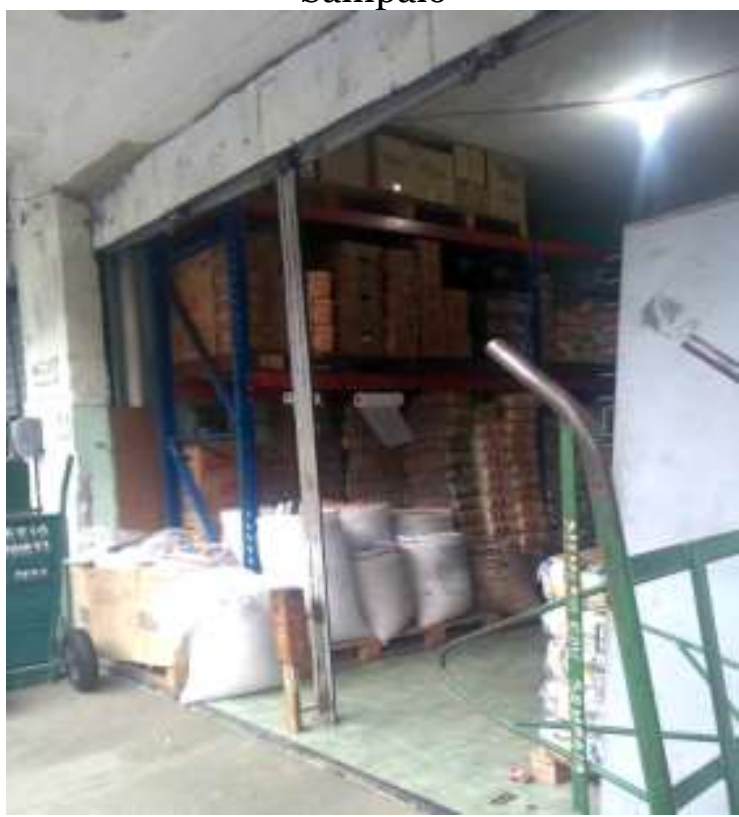

Fonte: Pesquisa Empírica, janeiro, 2018.

A logística integrada está conjugada à cadeia de suprimentos, pois “[...] envolve diferentes empresas que cooperam entre si [...]” (XAVIER, 2009, p. 97). Assim, "[...] a cadeia de suprimentos é constituída pelo caminho que se estende desde as fontes de matéria-prima, passando pelas fábricas de componentes, pela manufatura do produto e pelos distribuidores e varejistas, chegando finalmente ao consumidor" (XAVIER, 2009, p. 97-98 apud NOVAES, 1996, p. 38).

A cadeia de suprimentos está ligada aos circuitos espaciais da produção 4 e aos círculos de cooperação. As empresas atacadistas são o elo que articulam a distribuição da produção para o consumo final, dessa forma, participam de forma expressiva do abastecimento de estabelecimentos varejistas, sobretudo de mercearia básica, onde os dados da $\mathrm{ABAD} / 2017$, apontam para 53\% do abastecimento dos pequenos varejos. Assim, a logística é uma das modernizações que chegam até o ramo atacadista no intuito de gerar fluxo para distâncias cada vez maiores em tempo cada vez menores.

As modernizações nas bases materiais (máquinas, equipamentos e estruturas) são várias: empilhadeiras, transelevadores, armazéns automáticos, computadores com softwares avançados para coletar dados e ler códigos de barras entre outras. Elas fazem parte do rol das modernizações da automação da atividade.

Nas empresas atacadistas da Rua Governador Sampaio essas modernizações no maquinário coexistem. De um lado, empresas que utilizam computadores com softwares, elevadores, empilhadeiras para organização e escoamento das mercadorias (foto 3 e 4) frente às empresas que ainda utilizam equipamentos menos modernos que precisam de maior número de pessoas. Um exemplo é o uso de carrinhos de ferro manuseados por pessoas para transportar mercadorias dos caminhões para os armazéns e vice-versa que se contrapõem ao uso das empilhadeiras e elevadores (foto 5 e 6).

4 Santos (2008, p. 56), “circuitos espaciais de produção seriam as diversas etapas pelas quais passaria um produto, desde o começo do processo de produção até chegar ao consumo final”. 
Foto 3 - Mostrador de preço digital

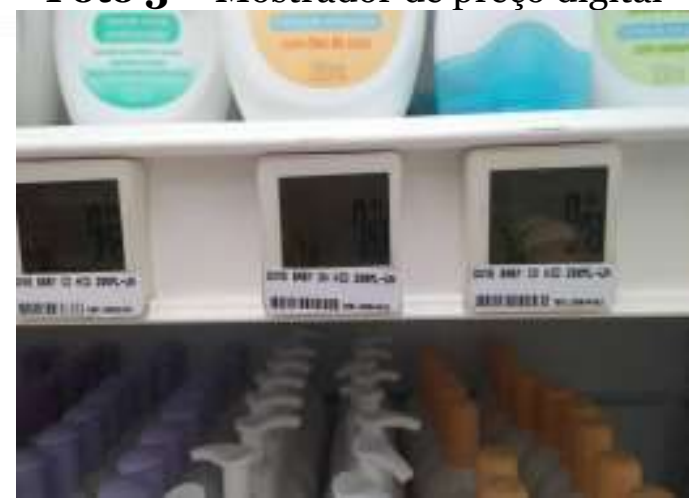

Fonte: Pesquisa Empírica, janeiro, 2018.

Foto 5 - Carregadores de mercadorias

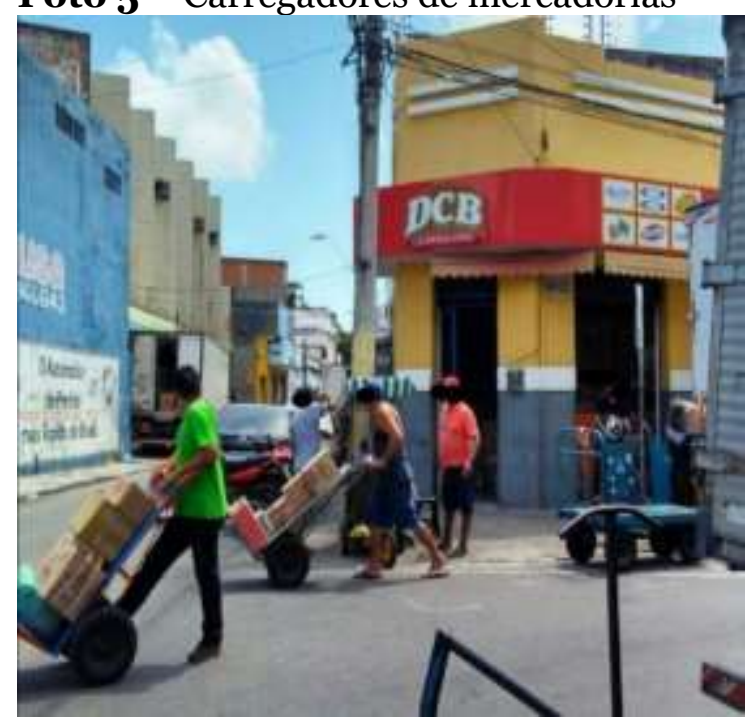

Fonte: Pesquisa Empírica, janeiro, 2018.

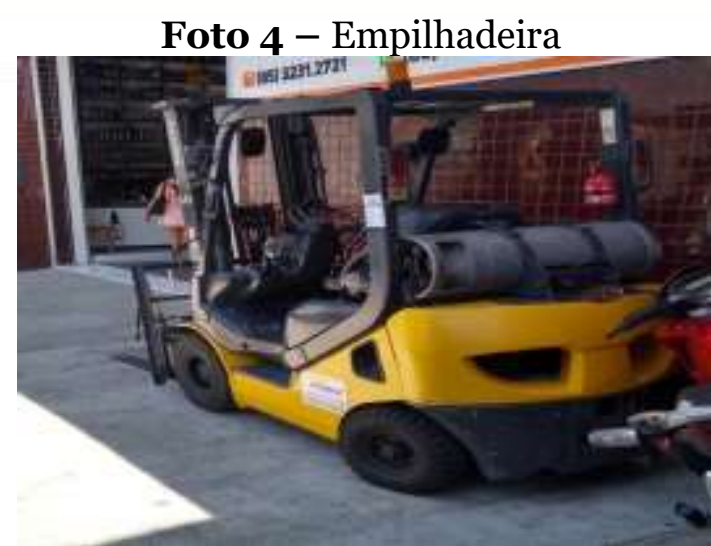

Fonte: Pesquisa Empírica, janeiro, 2018.

Foto 6 - Carrinhos de ferro

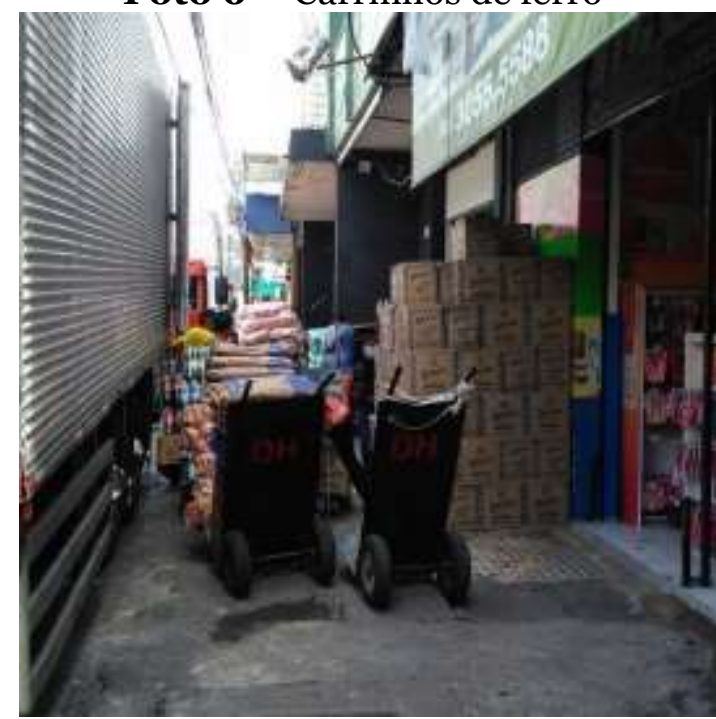

Fonte: Pesquisa Empírica, janeiro, 2018.

As fotos em destaque representam as permanências e as modernizações na Rua Governador Sampaio, ambas coexistindo. Na foto 3 podemos verificar um mostrador de preço digital com código de barras; na foto 4 uma empilhadeira que substitui a mão de obra humana no carregamento e empilhamento de mercadorias; na foto 5 a presença de carregadores de mercadorias na Rua; e na foto 6 carrinhos de ferro para transporte de mercadorias dos caminhões as empresas e vice-versa.

A diversidade dos produtos transacionados, a redução dos estoques, a distância e a capilaridade que caracterizam a localização dos milhares de pontos de venda do varejo, os pedidos mais freqüentes de quantidades menores e o aumento do número de itens que compõem o mix de produtos negociados têm tornado as operações de distribuição mais complexas e exigido uma nova forma de tratamento dos estoques (XAVIER, 2009, p. 107).

Essa colocação do autor trata de outra modernização importante do comércio atacadista - o armazenamento. Os armazéns concebidos para estocar grandes lotes de produtos vão cedendo espaço aos centros de distribuição, "[...] cujo foco central não é mais o de manter estoques, mas de fazê-los fluir" (XAVIER, 2009, p. 107). Dessa forma, os centros de distribuição se tornam fixos que geram fluxos.

No comércio atacadista da Rua Governador Sampaio, a atividade comercial ocorre toda no mesmo estabelecimento, desde o recebimento da mercadoria até a entrega

Lucas H. Rolim, Denise C. Bomtempo. Os circuitos da economia e o comércio atacadista na Rua Governador Sampaio/Fortaleza(CE) Brazilian Geographical Journal: Geosciences and Humanities research medium, Ituiutaba, v. 11, n. 2, p. 193-211, ago./dez. 2020. 
final. As modernizações dos grandes centros de distribuição (CD) que os comércios de grande porte e muitos supermercados e hipermercados possuem, não fazem parte da rotina dos atacadistas da referida Rua. Eles ainda utilizam seus galpões como armazém para estocagem e venda das mercadorias.

As mudanças na informação e no consumo permitiram que modernizações importantes ocorressem no comércio atacadista brasileiro como forma de se reinventar e permanecer competitivo no mercado. Essas mudanças também ocorrem em escalas menores, como na escala da Rua Governador Sampaio, mas podemos perceber que muitas delas não atingem todos os estabelecimentos. Uns se metamorfoseiam outros permanecem - todos coexistem.

\section{O COMÉRCIO ATACADISTA DA RUA GOVERNADOR SAMPAIO: UMA LEITURA DO PRESENTE}

O comércio atacadista desenvolvido na Rua Governador Sampaio é datado de mais de um século naquele espaço e ao longo do tempo passou por mudanças, que atingiu o setor atacadista de maneira geral. As modernizações não atingem os mesmos locais em espaçotempo e, desse modo, elas coexistem no espaço do atacado5. As empresas atacadistas estão divididas em: a) microempresa (ME), b) empresa de pequeno porte (EPP) e c) demais (quando a empresa não está vinculada à microempresa ou empresa de pequeno porte).

A Rua Governador Sampaio é caracterizada por diversos estabelecimentos comerciais, com predominância dos estabelecimentos atacadistas, que se articulam com diversas atividades. Estacionamentos, lanchonetes, restaurantes, mercearias, vilas residenciais, lojas de material escolar, lojas de produtos de beleza, farmácias, bombonieres, esmalterias, loja de ferragens, depósito de construção, armazéns com produtos regionais, salão de beleza, lojas de pallets, lojas de roupas, galerias antigas, onde se desenvolvem atividades comerciais voltadas a alimentação e residência, mini shopping, loterias, bicheiros nas calçadas, além do comércio de rua (carrinhos com lanches, com churrasco, com milho, com batatinhas) e os vendedores ambulantes fazem parte da paisagem da Rua.

De acordo com Rolim (2019), apesar de independentes, os estabelecimentos que não estão enquadrados no comércio atacadista - como o comércio varejista, restaurantes, lanchonetes, estacionamentos, entre outros, estão articuladas ao espaço do atacado, pois diferente das atividades varejistas realizadas na área core do Centro, a Rua Governador Sampaio fica afastada dessa área com maior fluxo de consumidores, o que gera "dependência" da atividade atacadista para que esses outros estabelecimentos consigam manter suas atividades.

Conforme classificação que utilizamos da Associação Brasileira de Atacadistas e Distribuidores (ABAD) as empresas estão divididas em três grupos: 1) os atacadistas de balcão: que são aqueles onde o cliente/consumidor se dirige até o estabelecimento e o atendimento da venda é realizado no balcão por um vendedor; 2) os atacadistas distribuidores: que o atendimento é realizado por meio de entrega da mercadoria ao estabelecimento do cliente; 3) os atacadistas de autosserviços: onde o cliente realiza a sua compra e se dirige ao caixa para efetuar o pagamento sem precisar do intermédio de um vendedor.

As classificações não são inflexíveis, no sentido de as operações serem realizadas apenas nesses modelos operacionais. O que queremos informar é que as classificações são de predominância e as operações da maioria dos estabelecimentos perpassam nas três formas. Ora realizam atendimento no balcão, mas com a entrega da mercadoria; ora realizam distribuição ao mesmo tempo em que estão atendendo no balcão. Vale destacar,

${ }^{5}$ Nomenclatura que utilizamos para classificar e caracterizar a articulação dos estabelecimentos atacadistas com os demais estabelecimentos que desenvolvem atividades comerciais ou de serviços na Rua.

Lucas H. Rolim, Denise C. Bomtempo. Os circuitos da economia e o comércio atacadista na Rua Governador Sampaio/Fortaleza(CE) Brazilian Geographical Journal: Geosciences and Humanities research medium, Ituiutaba, v. 11, n. 2, p. 193-211, ago./dez. 2020. 
também, a operação híbrida realizada nos estabelecimentos de auto serviço: o cliente compra a mercadoria abaixo do número mínimo estabelecido para venda no atacado, paga um preço diferente (a maior) do que o cliente que realiza a compra em maior quantidade. É a operação realizada na forma de atacarejo.

Os estabelecimentos instalados na rua voltados a atividade atacadista são múltiplos e os seus ramos também. No trabalho de campo, constatamos além dos estabelecimentos atacadistas do ramo mercearil (alimentos, bebidas, higiene pessoal e limpeza), estabelecimentos atacadistas que comercializam embalagens variadas (sacos, sacolas, material adesivo entre outros), estabelecimentos atacadistas que comercializam produtos de ferragens, estabelecimentos atacadistas que vendem medicamentos - farmácias, estabelecimentos atacadistas no ramo de festas, construção civil, artigos para armarinhos. Assim, conforme já constatado pela Prefeitura Municipal de Fortaleza, a Rua Governador Sampaio ainda é lócus do comércio atacadista realizado no Centro da cidade de Fortaleza.

No Cartograma 2 observamos o recorte espacial da Rua Governador Sampaio onde o comércio atacadista é desenvolvido.

Cartograma 1 - Caracterização da Rua Governador Sampaio (2019)

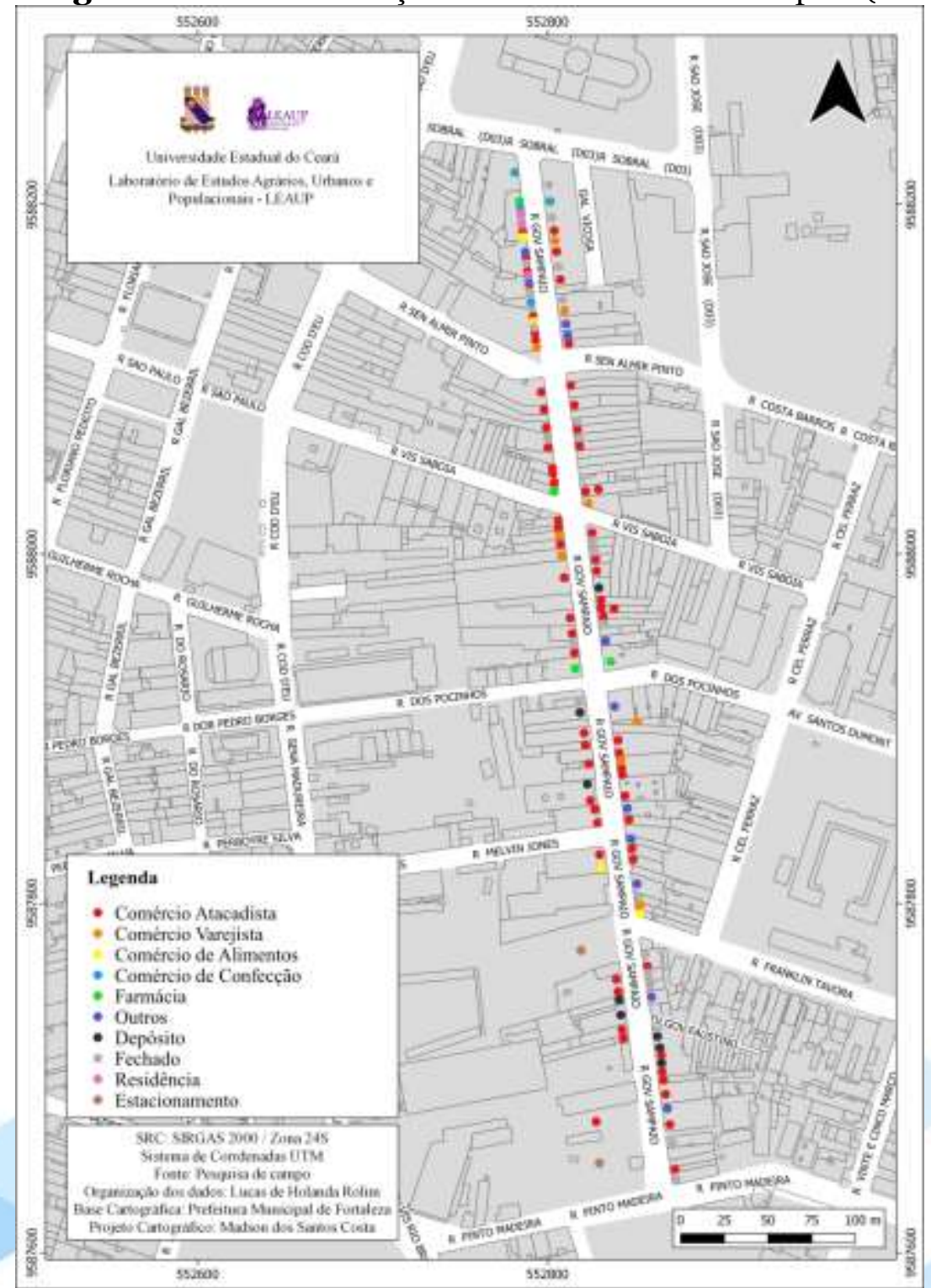

Fonte: Pesquisa Empírica, 2019. ORG.: ROLIM, Lucas de Holanda. 2019.

Lucas H. Rolim, Denise C. Bomtempo. Os circuitos da economia e o comércio atacadista na Rua Governador Sampaio/Fortaleza(CE) Brazilian Geographical Journal: Geosciences and Humanities research medium, Ituiutaba, v. 11, n. 2, p. 193-211, ago./dez. 2020 
A Rua tem predominância do comércio atacadista, conforme se observa nos pontos vermelhos do Cartograma 2. São 163 estabelecimentos entre comerciais e residenciais: $53 \%$ correspondem ao comércio atacadista; $18 \%$ correspondem aos estabelecimentos fechados (com placa de aluguel, venda ou sem placa); $15 \%$ correspondem ao comércio varejista; $8 \%$ correspondem a outras atividades (loterias, salão de beleza ou atividades que não conseguimos identificar); $6 \%$ correspondem a residências (declarados em entrevistas ou com placas de aluga apartamento e/ou kitnet).

A partir da pesquisa empírica, percebemos que a atividade atacadista, apesar de predominante na paisagem da Rua, mostrava-se com algumas precariedades, sobretudo do ponto de vista infra estrutural. Identificamos problemas na circulação de mercadorias e pessoas (foto 7) - a Rua é estreita para os fluxos existentes: de caminhões, carregadores de mercadorias, clientes e transeuntes, o que cria uma barreira ao desenvolvimento da atividade, já que diferente da atividade varejista em geral, a atividade atacadista movimenta maior quantidade de mercadorias tanto no abastecimento dos estabelecimentos atacadistas (as mercadorias que chegam de outras distribuidoras e da indústria) quanto na distribuição das mercadorias (as mercadorias que são distribuídas pelos atacadistas distribuidores e compradas pelos clientes que realizam a compra no balcão). Alguns estabelecimentos fechados com a placa de aluga ou de venda indicando uma diminuição da atividade no local - o que foi constatado pela leitura dos estudos da Prefeitura de Fortaleza, em trabalho de campo e em depoimentos de donos de estabelecimentos.

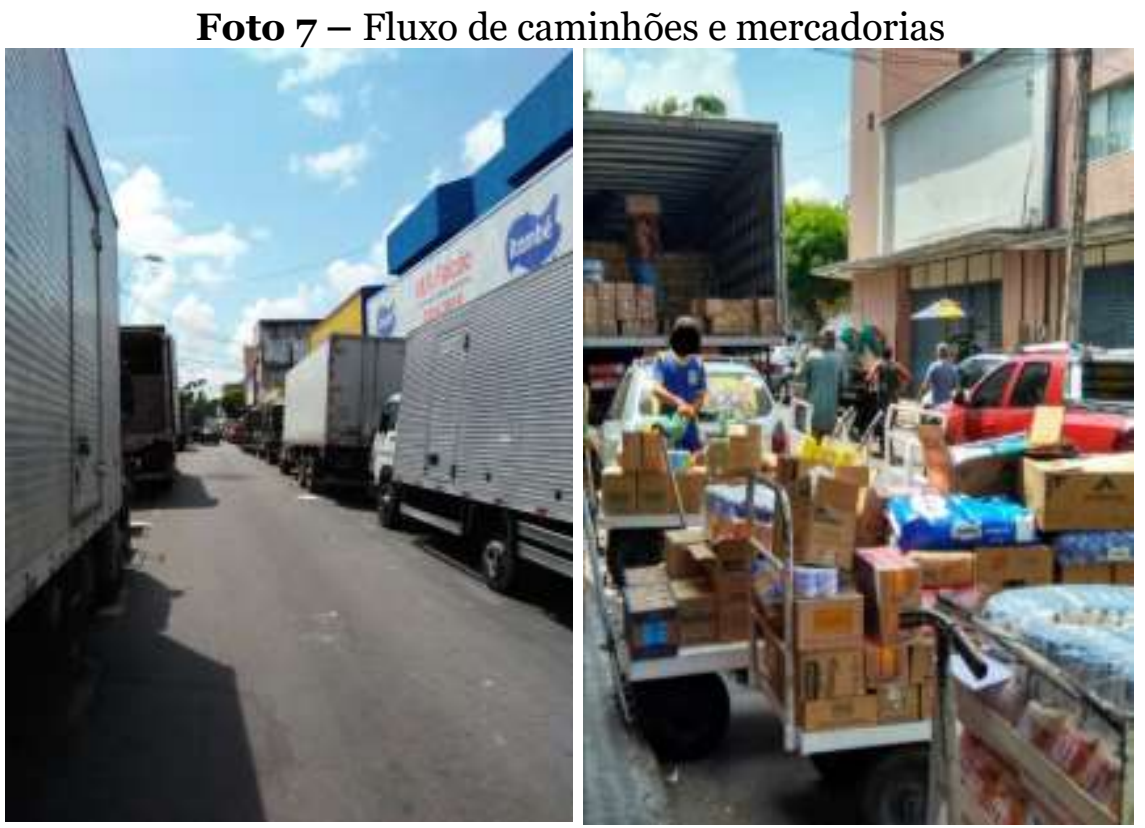

Fonte: Pesquisa Empírica, fevereiro, 2019.

Apesar dos problemas enfrentados, o comércio da Rua Governador Sampaio se articula. Os dois estacionamentos instalados na Rua, por exemplo, servem de ponto de apoio aos clientes que vão até os estabelecimentos realizar negociação. Além disso, alguns estabelecimentos fecham parceria com eles para atender a demanda dos clientes em deixar seus veículos mais próximos para facilitar o deslocamento da mercadoria. Para além do uso dos clientes, eles servem para abrigar, também, os veículos dos proprietários e funcionários das empresas.

Outra articulação que podemos perceber na rua são os comércios voltados à alimentação (restaurantes lanchonetes e carrinhos de lanches) - foto 8. No trabalho de 
campo realizamos entrevistas com proprietárias e proprietários de três estabelecimentos e, conforme relatado, a maior parte da sua clientela, quase 90\%, são dos trabalhadores do comércio atacadista, principalmente os que realizam os transportes das mercadorias - os carregadores. Desse modo, é possível destacar a dependência do circuito inferior em relação ao circuito superior (SANTOS, 2008).

Foto 8 - Restaurante e carrinho de churrasco na Rua Governador Sampaio

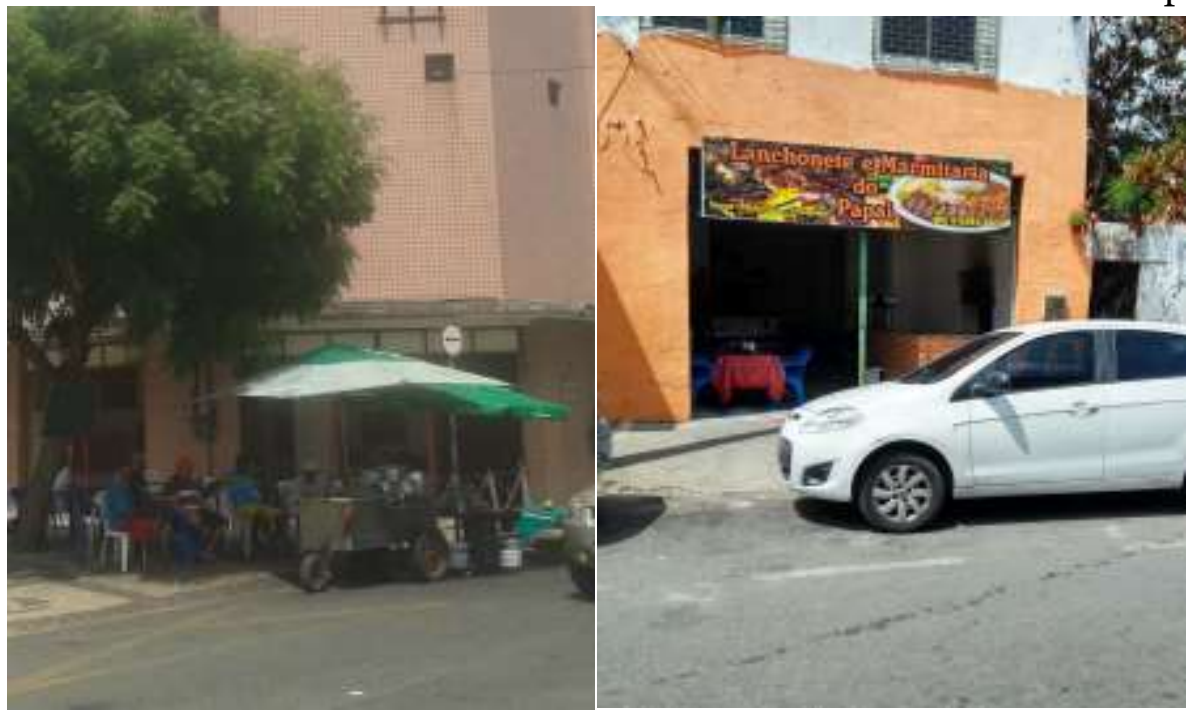

Fonte: Pesquisa Empírica, fevereiro, 2019.

O comércio alimentício de Rua também pode ser observado. Constatamos sete carrinhos com alimentos variados (churrasco, pratinho ${ }^{6}$, milho cozido e assado, batata frita, entre outros) que confirma a dependência das atividades do circuito inferior da economia urbana em relação ao superior e, destaca a articulação que o espaço do atacado possui com as diversas atividades. Realizamos uma entrevista com o Marcos7, vendedor de churrasquinho, e ele informou que mora próximo ao espaço e viu ali uma oportunidade para ganhar uma renda extra. Trabalhando como vigilante em escala de 12 por 36 horas, ele encontrou nos dias de folga a oportunidade de comercializar os churrascos naquele espaço.

Isso confirma a afirmação de Santos (2008):

[..] da definição dos circuitos não é rígida, tendo em vista que todas as camadas da população podem consumir fora do circuito a que pertencem", podendo ser um consumo parcial ou ocasional. Além disso, pessoas mais diretamente ligadas ao circuito inferior vendem temporariamente ou ocasionalmente sua força de trabalho no circuito superior (SANTOS, 2008, p. 42).

As articulações na Rua Governador Sampaio, como mostradas, são múltiplas e atendem às diversas demandas. As empresas instaladas no espaço do atacado, apesar de independentes, articulam-se, sobretudo, as que não realizam atividades atacadistas, que, excetuando o setor de confecção, que está adentrado à Rua, pois já transborda nas proximidades da Igreja da Sé, têm dependência direta com o desenvolvimento das atividades das empresas atacadistas.

${ }^{6}$ Um prato típico do Ceará, em que a comida, geralmente, arroz, creme de frango, vatapá, verdura crua ou cozida e farofa é colocada em um pequeno prato de plástico descartável.

7 Nome fictício utilizado para não revelar a identidade do vendedor.

Lucas H. Rolim, Denise C. Bomtempo. Os circuitos da economia e o comércio atacadista na Rua Governador Sampaio/Fortaleza(CE) Brazilian Geographical Journal: Geosciences and Humanities research medium,

Ituiutaba, v. 11, n. 2, p. 193-211, ago./dez. 2020

Página | 208 


\section{CONSIDERAÇÕES FINAIS}

Os circuitos da economia urbana interagem entre si e a atividade atacadista age como elo entre eles. A crescente ascensão da população de baixa renda ao consumo e à expansão do pequeno varejo ocasionada por esta resulta da exclusão de parte da população ao comércio moderno e ao emprego. A modernização das atividades produtivas gerou demandas e possibilidades de expansão no território nacional, assim, para atingir locais que as mesmas não conseguiam, usaram os atacadistas para realizarem essa extensão.

As modernizações que ocorreram e atingiram a atividade atacadista nos últimos trinta anos não atingiram de forma integral todos os estabelecimentos atacadistas que desenvolvem atividades na Rua. Mudanças e permanências são percebidas, sobretudo, por se tratar de uma atividade secular com resquícios do espaço-tempo do século passado. A atividade secular se metamorfoseia, mas também permanece e nessas mudanças - coexistem entre si.

Os armazéns que realizavam a atividade de distribuição das mercadorias na praça comercial de Fortaleza no século XIX e século XX, nos moldes tradicionais de comercialização, ainda trazem marcas na paisagem do espaço do atacado - definido na nossa pesquisa como a articulação dos estabelecimentos atacadistas com as demais atividades comerciais desenvolvidas na Rua. O comércio atacadista da Rua Governador Sampaio coexiste com as modernizações e se metamorfoseiam e, ainda, resiste à entrada das grandes redes atacadistas de autosserviço em Fortaleza nos últimos dez anos, encontra abrigo no território onde essas empresas não alcançam ou não tem interesse e permanecem.

O comércio atacadista da Rua Governador Sampaio, apesar de apresentar algumas precariedades infra estruturais, continua com expressividade no espaço do atacado, articula diversas atividades, sobretudo, do circuito inferior: restaurantes, lanchonetes e comércio ambulante, gera diversos fluxos - dentro da rua, intra-urbano e interurbano, e realiza abastecimento de pequenos varejos, bares, lanchonetes e restaurantes dispersos no entorno do Centro, bairros periféricos da cidade, municípios da Região Metropolitana de Fortaleza (RMF) e outros municípios do Estados. E dentro das formas mais significativas do comércio atacadista classificado pela $\mathrm{ABAD}$, desenvolve as suas atividades em três: distribuidoras, de balcão e autosserviço.

\section{BIBLIOGRAFIA}

CORREAA, Roberto Lobato. Estudos sobre a rede urbana. Rio de Janeiro: Bertrand Brasil, 2006.

COSTA, Maria Clélia Lustosa. Expansão da infra-estrutura urbana e dos serviços públicos em Fortaleza (Brasil), na virada do século XIX. In: ENCONTRO DE GEÓGRAFOS DA AMÉRICA LATINA, 10, 2005, São Paulo. Anais... São Paulo: Universidade de São Paulo, 2005. p.3765-3781.

COSTA, Maria Clélia Lustosa. Planejamento e Expansão Urbana. In: DANTAS, Eustógio Wanderley Correia; SILVA, José Bozzarchielo da; COSTA, Maria Clélia Lustosa. (orgs). De cidade à metrópole: (trans) formações urbanas em Fortaleza. Fortaleza: Edições UFC, 2009.

DANTAS, Eustógio Wanderley Correia. O centro de Fortaleza na Contemporaneidade. In: DANTAS, Eustógio Wanderley Correia; SILVA, José Bozzarchielo da; COSTA, Maria

Lucas H. Rolim, Denise C. Bomtempo. Os circuitos da economia e o comércio atacadista na Rua Governador Sampaio/Fortaleza(CE) Brazilian Geographical Journal: Geosciences and Humanities research medium, Ituiutaba, v. 11, n. 2, p. 193-211, ago./dez. 2020. 
Clélia Lustosa. (orgs). De cidade à metrópole: (trans) formações urbanas em Fortaleza. Fortaleza: Edições UFC, 2009.

FORTALEZA, Prefeitura Municipal. Estudo das Vantagens Competitivas do Centro da Cidade de Fortaleza. Relatório o5: Diagnóstico Das Vantagens Competitivas. Fortaleza: Prefeitura Municipal de Fortaleza,2004.

LEMENHE, Maria Auxiliadora. As razões de uma cidade. Fortaleza: Stylos comunicações, 1991.

LINHARES, Paulo. Cidade de água e sal: por uma antropologia do litoral do nordeste sem cana e sem açúcar. Fortaleza: Demócrito Rocha, 1992.

MONTENEGRO, Marina Regitz. O circuito inferior da economia urbana na cidade de São Paulo no período da globalização. 2006, 205f. Dissertação (Mestrado em Geografia) - Universidade de São Paulo, São Paulo, 2006.

MONTENEGRO, Marina Regitz. Globalização, trabalho e pobreza no Brasil metropolitano. O circuito inferior da economia urbana em São Paulo, Brasília, Fortaleza e Belém. 2011, 303f. Tese (Doutorado em Geografia) Universidade de São Paulo, São Paulo, 2011.

QUEIROZ, Priscilla Régis Cunha de. Trabalho e Cotidiano: produção e comércio de gêneros Alimentícios em Fortaleza, no final do XIX e início do XX. 2011, $200 f$. Dissertação (Mestrado em História) - Universidade Federal do Ceará, Fortaleza, 2011.

ROLIM, Lucas de Holanda. Economia urbana e comércio atacadista na Rua Governador Sampaio, Centro de Fortaleza/CE, 2019. 113f. Trabalho de Conclusão de Curso (Graduação em Geografia) - Universidade Estadual do Ceará, Fortaleza, 2019.

SANTOS, Milton. Economia espacial: críticas e alternativas. 2. ed. São Paulo: EDUSP, 2011.

SANTOS, Milton. O Espaço Dividido: os dois circuitos da economia urbana dos países subdesenvolvidos. 2. ed. 2. Reimpressão. Rio de Janeiro: F. ALVES, 2018.

SANTOS, Milton. Metamorfoses do espaço habitado: Fundamentos Teóricos e Metodológicos

da Geografia, 6 ed. São Paulo: Edusp, 2008.

SILVA, José Bozzarchielo da. Formação Socioespacial Urbana. In: DANTAS, Eustógio Wanderley Correia; SILVA, José Bozzarchielo da; COSTA, Maria Clélia Lustosa. (orgs). De cidade à metrópole: (trans) formações urbanas em Fortaleza. Fortaleza: Edições UFC, 2009.

SILVEIRA, Maria Laura. Globalización y circuitos de la economía urbana en ciudades brasileñas. Cuadernos del Cendes. Caracas, v. 21 n.57, p.1-21, set. 2004. Disponível em: < www.scielo.org.ve/scielo.php> Acesso em: $29 \mathrm{dez} 2018$

SILVEIRA, Maria Laura. Finanças, consumo e circuitos da economia urbana na cidade de São Paulo. Caderno CRH, Salvador, v. 22, n. 55, p. 65-76, Jan./Abr. 2009.

SOUZA, Maia Salete. Análise da Estrutura Urbana. In: DANTAS, DANTAS, Eustógio Wanderley Correia; SILVA, José Bozzarchielo da; COSTA, Maria Clélia Lustosa. (orgs). 
De cidade à metrópole: (trans) formações urbanas em Fortaleza. Fortaleza: Edições UFC, 2009.

XAVIER, Marcos Antônio de Moraes. Os elos entre os circuitos da economia urbana brasileira no atual período: os atacadistas distribuidores e seu papel intermediador, 2009, 222f. Tese (Doutorado em Geografia) - Universidade Estadual de Campinas, Campinas, SP, 2009.

Recebido em: 19/10/2020. Aprovado para publicação em: 28/12/2020. 